\title{
Early ontogeny shows the same interspecific variation as natural history parameters in the crested newt (Triturus cristatus superspecies) (Caudata, Salamandridae)
}

\author{
Milena Cvijanović ${ }^{1,3}$, Ana Ivanoviće, ${ }^{2,}$ Nataša Tomašević Kolarov ${ }^{1}$, Georg Džukić1 ${ }^{1}$, Miloš L. Kalezić1,2 \\ ${ }^{1}$ Department of Evolutionary Biology, Institute for Biological Research "Siniša Stanković”, University of Belgrade, \\ Bulevar Despota Stefana 142, 11060 Belgrade, Serbia \\ ${ }^{2}$ Institute of Zoology, Faculty of Biology, University of Belgrade, Studentski trg 16, 11000 Belgrade, Serbia \\ ${ }^{3}$ E-mail:milena.cvijanovic@ibiss.bg.ac.rs \\ ${ }^{4}$ E-mail:ana@bio.bg.ac.rs
}

Key words: developmental correlations, developmental sequences, life-history, ontogenetic trajectories

\begin{abstract}
When the phenotypic divergence within a monophyletic group is characterised by parallel variation of different phenotypic traits, it is very likely that the environment through constraints and/or selection has affected the developmental pathways simultaneously. Such patterns of phenotypic divergence characterise the phenotypic evolution of the crested newts (Triturus cristatus superspecies). In this study, we have examined interspecific variations in the embryonic development of four crested newt species. The species are similar with respect to some basic developmental traits, some morphologically defined developmental stages and the survival rate during early embryogenesis. However, there is significant variation in the developmental rate, as well as differences in the pattern of correlation amongst analysed life-history and developmental traits. Consistent with previous studies, T. dobrogicus appears to be an outlier species, with the longest embryonic period and a significantly different correlation pattern for early life-history and developmental traits. We suggest that the invasion of a novel aquatic environment by $T$. dobrogicus resulted in large-scale directional changes in development, which could explain parallel change in numerous phenotypic and life-history traits with a high rate of evolution.
\end{abstract}

\section{Contents}

Introduction 43

Materials and methods ............................................................... 44

Experimental design and sampling ..................................... 44

Analysed traits ......................................................................... 44

Statistical analyses .................................................................. 45

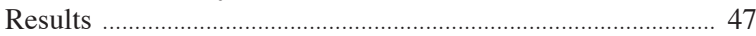

Survival rate ........................................................................... 47

Developmental and early life-history correlation patterns 47

Interspecific variability in embryonic development ......... 47

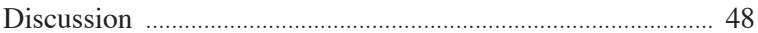

Acknowledgements ............................................................... 49

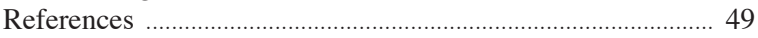

\section{Introduction}

There is a common premise that evolutionarily related groups must show phenotypic similarity, including shared developmental basis, inherited from a common ancestor. When the phenotypic divergence within a monophyletic group shows parallel evolution of multiple phenotypic traits, it is most likely the case that the environment, through constraint and/or selection, affected the developmental pathways simultaneously, causing covariation between different phenotypic traits (see Hansen and Martins, 1996; Klingenberg, 2004; Revell et al., 2008). This line of reasoning is especially strong in situations where the interspecific variations in ecological demands correlate to the variations in other phenotypic traits. Such a pattern of divergence characterises the evolution of crested newts (Triturus cristatus superspecies).

The crested newts form a well-supported monophyletic clade within the European newts (e.g., Espregueira Themudo et al., 2009). This group consists of six species: T. cristatus (Laurenti, 1768); T. dobrogicus (Kiritzescu, 1903); T. karelinii (Strauch, 1870); T. arntzeni Litvinchuk, Borkin, Džukić and Kalezić, 1999, which has been recently elevated to the species level (Espregueira Themudo et al., 2009); and two more closely related species - T. carnifex (Laurenti, 1768) and T. macedonicus (Karaman, 1922) (see Arntzen et al., 2007). Evolutionary splitting between these species is thought to have occurred within a short time span (Arntzen et al., 2007; Espregueira Themudo et al., 2009). The crested newt species differ in their ecological demands (Arntzen, 2003; Litvinchuk et al., 2007), with $T$. dobrogicus at one 
pole, T. karelinii, T. arntzeni, T. carnifex and T. macedonicus at the other pole, and T. cristatus as an intermediate species. Some morphological characteristics have been broadly used for the phenotypic differentiation of these species, such as body size and shape (Arntzen and Wallis, 1999), skull shape as inferred by geometric morphometrics (Ivanović et al., 2008a), number of rib-bearing vertebrae (Crnobrnja-Isailović et al., 1997; Arntzen and Wallis, 1999), relation between braincase and body size (Vukov et al., 2007), egg size (Furtula et al., 2008), limb skeleton (Ivanović et al., 2008b), pattern of sexual size dimorphism (Ivanović et al., 2008c), and life-history traits (Furtula et al., 2009). All of these results point to the parallel evolution of a number of phenotypic and life-history traits, which follow a similar trend to species-specific ecological demands.

Thus far, the embryonic development of the crested newts has received very little attention. In particular, comparative embryology to date (e.g., Griffiths and Wijer, 1994; D'Amen et al., 2007; Litvinchuk et al., 2007), especially quantitative data, has been insufficient to infer interspecific variation in early ontogeny. In this study, we applied a quantitative approach to investigate the embryonic development of four crested newt species (T. dobrogicus, T. arntzeni, T. macedonicus and T.cristatus), which represent the main phylogenetic clades (Espregueira Themudo et al., 2009). We compared rates of development and the correlation patterns of several early life-history traits in order to quantify and explore variation in the early ontogeny of crested newts. The results of this study show that crested newts offer a unique paradigm in which to investigate the evolutionary basis for developmental changes within an ecological context.

\section{Materials and methods}

\section{Experimental design and sampling}

Two great advantages of using newts for experimental analysis are that European newt females, including crested newts, deposit their eggs one by one and embryonic development occurs in transparent mucoid capsules, making the tracing of developmental stages easy and accurate (Nieuwkoop, 1996).

We collected large, gravid females with inflated abdomens and swollen cloacae from natural populations of four species prior to the oviposition period. Females of T. macedonicus $(N=7)$ were collected in
March 2008: six originated from Ceklin $\left(42^{\circ} 21^{\prime} \mathrm{N}\right.$; $18^{\circ} 59^{`} \mathrm{E}, 290 \mathrm{~m}$ above sea level (a.s.l.)) and one female from nearby Donji Ljubotinj $\left(42^{\circ} 23^{\prime} \mathrm{N}, 19^{\circ} 07^{\prime} \mathrm{E}, 225\right.$ m a.s.l.), Montenegro. Females of T. arntzeni $(N=8)$ were collected in April 2008 from Borovsko polje, Serbia $\left(42^{\circ} 58^{\prime} \mathrm{N}, 2^{\circ} 43^{\prime} \mathrm{E}, 890 \mathrm{~m}\right.$ a.s.1.). Females of T. dobrogicus $(N=4)$ were collected near Kikinda

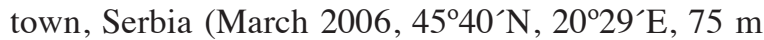
a.s.1.). Females of $T$. cristatus females $(N=6)$ were collected in April 2006: five females were taken from Miroč, Serbia $\left(44^{\circ} 29^{\prime} \mathrm{N}, 22^{\circ} 20^{\prime} \mathrm{E}, 440 \mathrm{~m}\right.$ a.s.l.), and one female from Vršački breg, Korkana $\left(45^{\circ} 06^{\prime} \mathrm{N}\right.$, $21^{\circ} 27^{\prime} \mathrm{E}, 180 \mathrm{~m}$ a.s.1.). The females were transferred to a laboratory at the Institute of Biological Research, University of Belgrade, within $24 \mathrm{~h}$. All females were returned to their original population sites after the oviposition period ended.

Since crested newt species prefer different temperatures (Litvinchuk et al., 2007), we provided two different experimental temperature conditions when examining interspecific differences in embryonic development. Triturus dobrogicus and T. cristatus were kept at $16-17^{\circ} \mathrm{C}$, while the more thermophylic species T. macedonicus and T. arntzeni were kept at $18-19^{\circ} \mathrm{C}$. Since the duration of European newt embryonic development correlates with temperature (Griffiths and Wijer, 1994; Bonacci et al., 2005; D'Amen et al., 2007), temperatures were kept constant to provide similar ecological settings for all individuals during embryonic development. In the laboratory, females were housed individually in 12-litre aquaria containing six litres of dechlorinated tap water. The captive females were fed every other day with worms and Tubifex. Plastic strips were provided for egg deposition and eggs were collected daily. Eggs were allowed to develop under laboratory conditions in Petri dishes $(5 \mathrm{~cm}$ in diameter) containing a maximum of 10 eggs per Petri dish and filled with enough dechlorinated tap water to cover the eggs. The water was changed every second day.

\section{Analysed traits}

The eggs deposited by one female over a $24 \mathrm{~h}$ period were used as cohorts, and the mean values of analysed traits were calculated separately for each cohort. Eggs were photographed immediately after removal from the plastic strips for measurements. The morphologically defined developmental events (stages of embryonic development) were established according to a description of embryonic stages for $M$. alpestris 
(Knight, 1938; see also Epperlein and Junginger, 1982). To estimate the variation in timing of developmental events within and between species, the developing embryos were examined under a binocular microscope by M. C. and N. T. K. at three different time points: at 7,11 and 15 days following egg laying. The embryonic developmental stage was recorded at each particular checkpoint (at day 7, 11, and 15 of embryonic development), hereafter designated as S7, S11 and S15, respectively. Such experimental design provided a basis for analysing the variation in developmental events and developmental rates within and between species. Undeveloped eggs and dead embryos were removed regularly. Due to the possible effect of signalling between embryos on embryonic induction (Hall, 1999; 2003), median values for recorded stages of embryos per Petri dish (up to 10 embryos) were calculated; these data were used in further analyses. Hatched larvae were photographed with a digital camera (Nikon Coolpix 4500) and a 10-mm scale bar to measure the total length of larvae.

The following eight life-history traits were recorded: time of egg deposition relative to the oviposition period (DO), number of eggs laid per cohort (NE), mean vitellus diameter per cohort (RV), volume of galerta calculated as a difference among egg's volume and vitellus volume (VG), number of hatched larvae per cohort $(\mathrm{NH})$, total length of hatched larvae per cohort (TL), duration of embryonic period of embryos per cohort (EP) and total hatchling survival rate of embryos per cohort (SR). Measurements of egg and vitellus diameter and TL of hatched larvae were taken by M. C. using UTHSCSA IMAGETOOL version 3.0 (http://ddsdx.uthscsa.edu/dig/itdesc.html).

\section{Statistical analyses}

To investigate the pattern of mortality during the embryonic period, we estimated survival rate (SR) as a proportion of live embryos recorded between two checkpoints. Survival rate confidence intervals were calculated according to the following formula:

$C I=2 \sqrt{\frac{q(1-q)}{n}}$

where $q=1-\mathrm{SR}, \mathrm{SR}$ is the survival rate and $n$ is number of eggs at the beginning of the experiment. Two survival rates were considered significantly different (at 0.95 level) when respective confidence intervals did not overlap (Geller, 1983; Miaud, 1994).
To investigate the relationship between recorded life-history traits for each cohort (NE, RV, VG, SR, TL, EP), as well as between recorded developmental stages of embryos at each particular checkpoint (S7, S11, S15), we calculated Pearson correlation coefficients between these traits separately for each species. The pattern of correlation between recorded traits was analysed with matrix correlations. The similarity of these correlations between species was tested using Quadratic Assignment Procedures (Mantel's test) with 10,000 iterations. The significance test is based on the null hypothesis of no similarity in correlation patterns between compared matrices. A significant correlation between matrices would suggest a non-negligible concordance in correlation pattern between compared matrices.

Matrix correlations were used to estimate the degree of correspondence between interspecies observed correlation patterns and to estimate the robustness of observed correlations. We estimated the robustness and repeatability of observed correlation matrices using the resampling with replacement, or "bootstrapping", method (Cheverud et al., 1989; Marroig and Cheverud, 2001). For each species of sample size $n$, $n$ samples were randomly resampled with replacements from the original dataset. This procedure was repeated 500 times (Efron and Tibshirani, 1993), and 500 bootstrap datasets were generated separately for each species using Poptools 2.62 (Hood, 2004). For each generated dataset, correlation matrices were calculated and compared with the correlation matrix obtained from the original data using a matrix correlation. The frequency distributions of matrix selfcorrelations were used to estimate the robustness of correlation matrices. The repeatability of matrix selfcorrelations were used to estimate the theoretical maximum matrix correlation $\left(R_{\max }\right)$ and to obtain an adjusted matrix correlation $\left(R_{\text {adj }}\right)$ between two observed matrices (Marroig and Cheverud, 2001). The value of $R_{\max }$ was calculated as $\left(\mathrm{t}_{\mathrm{A}} \mathrm{t}_{\mathrm{B}}\right)^{0.5}$, where $\mathrm{t}_{\mathrm{A}}$ and $\mathrm{t}_{\mathrm{B}}$ denoted the mean of the matrix self-correlations of matrices $\mathrm{A}$ and $\mathrm{B}$, respectively. The adjusted matrix correlation $\left(R_{\text {adj }}\right)$ was calculated as the observed correlation between two matrices $\left(R_{\mathrm{obs}}\right)$ divided by the maximum matrix correlation $\left(R_{\max }\right)$.

Since temperature is one of the most important variables affecting amphibian embryonic development, direct comparisons of embryonic developmental timing between different species must be assayed at the animals' preferred developmental temperatures (Bonacci et al., 2005; D'Amen et al., 2007). Taking 
Table 1. Mean values, standard deviations (mean $\pm \mathrm{SD}$ ) and coefficients of variation $(\mathrm{CV})$ for analysed life-history traits are presented for total number of eggs and larvae $(\mathrm{N})$. Also given are the survival rate $(\mathrm{r})$ and the confidence interval $(\mathrm{CI})$ of survival rate at three checkpoints ( $\mathrm{I}=7$ days, $\mathrm{II}=11$ days and $\mathrm{III}=15$ days $)$ during embryonic development, as well as the total hatching success rate.

\begin{tabular}{|c|c|c|c|c|c|c|c|c|c|c|c|c|}
\hline \multirow[b]{3}{*}{ Life history traits } & \multicolumn{3}{|c|}{ T.macedonicus } & \multicolumn{3}{|c|}{ T. arntzeni } & \multicolumn{3}{|c|}{ T. dobrogicus } & \multicolumn{3}{|c|}{ T. cristatus } \\
\hline & $N$ & mean \pm SD & $\mathrm{CV} \%$ & $N$ & mean \pm SD & $\mathrm{CV} \%$ & $N$ & mean \pm SD & $\mathrm{CV} \%$ & $N$ & mean $\pm \mathrm{SD}$ & $\mathrm{CV} \%$ \\
\hline & & & & & & & & & & & & \\
\hline Diameter of vitellus (mm) & 857 & $1.95 \pm 0.38$ & 19.31 & 293 & $1.87 \pm 0.12$ & 6.25 & 657 & $1.55 \pm 0.07$ & 4.70 & 143 & $1.87 \pm 0.15$ & 7.83 \\
\hline Volume of galerta $\left(\mathrm{mm}^{3}\right)$ & 857 & $9.87 \pm 1.76$ & 17.80 & 293 & $7.53 \pm 2.39$ & 31.73 & 657 & $6.59 \pm 1.86$ & 28.20 & 143 & $11.51 \pm 4.47$ & 38.82 \\
\hline TL of hatched larvae (mm) & 319 & $11.36 \pm 0.64$ & 5.67 & 65 & $9.70 \pm 0.29$ & 3.03 & 126 & $9.25 \pm 0.57$ & 6.12 & 26 & $9.97 \pm 0.71$ & 7.10 \\
\hline Embryonic period (days) & 319 & $20.01 \pm 1.51$ & 7.55 & 65 & $16.96 \pm 1.36$ & 8.04 & 126 & $26.10 \pm 1.44$ & 5.51 & 26 & $21.80 \pm 2.18$ & 10.02 \\
\hline Survival rate & & $\mathrm{r}$ & $\mathrm{CI}$ & & $\mathrm{r}$ & $\mathrm{CI}$ & & r & $\mathrm{CI}$ & & $\mathrm{r}$ & $\mathrm{CI}$ \\
\hline At checkpoint I & & 0.79 & $0.76-0.82$ & & 0.61 & $0.55-0.67$ & & 0.39 & $0.35-0.43$ & & 0.47 & $0.39-0.55$ \\
\hline Between checkpoint I and II & & 0.98 & $0.97-0.99$ & & 0.86 & $0.81-0.91$ & & 0.95 & $0.93-0.98$ & & 0.94 & 0.88-0.99 \\
\hline Between checkpoint II and III & & 0.49 & $0.46-0.53$ & & 0.42 & $0.34-0.50$ & & 0.54 & $0.48-0.60$ & & 0.58 & $0.45-0.70$ \\
\hline Between checkpoint III and hatchin & & 0.97 & $0.95-0.99$ & & 1.00 & / & & 0.90 & $0.85-0.95$ & & 0.70 & $0.55-0.85$ \\
\hline Total hatching success rate & & 0.37 & $0.15-0.21$ & & 0.22 & $0.17-0.27$ & & 0.18 & $0.15-0.21$ & & 0.18 & $0.12-0.25$ \\
\hline
\end{tabular}

Table 2. Pearson's correlation coefficients between 11 analyzed traits. (a) T. macedonicus, number of cohorts $N=91$ (upper diagonal) and T. arntzeni, number of cohorts $N=34$ (lower diagonal) and (b) T. cristatus, number of cohorts $\mathrm{N}=19$ (upper diagonal) and T. dobrogicus, number of cohorts $N=76$ (lower diagonal). Pearson's correlation coefficients were calculated from averaged data from each cohort (eggs laid by females during one day). Statistically significant correlation coefficients $(\mathrm{P}<0.05)$ are in bold. Abbreviations are explained in the Materials and methods section.

\begin{tabular}{|c|c|c|c|c|c|c|c|c|c|c|c|}
\hline & DO & $\mathrm{NE}$ & RV & VG & S7 & S11 & S15 & $\mathrm{NH}$ & TL & EP & V \\
\hline $\mathrm{DO}$ & & -0.13 & -0.38 & 0.54 & 0.54 & 0.18 & 0.24 & 0.07 & -0.04 & -0.36 & 0.22 \\
\hline $\mathrm{NE}$ & -0.17 & & 0.12 & 0.15 & 0.09 & -0.07 & 0.07 & 0.74 & 0.00 & -0.10 & -0.27 \\
\hline RV & 0.42 & -0.18 & & -0.12 & 0.14 & -0.02 & 0.02 & -0.02 & 0.01 & -0.19 & -0.20 \\
\hline VG & -0.55 & 0.43 & 0.03 & & 0.53 & 0.03 & 0.01 & 0.21 & -0.02 & -0.39 & 0.03 \\
\hline S7 & 0.17 & 0.18 & 0.53 & 0.28 & & 0.38 & 0.36 & 0.35 & 0.03 & -0.44 & 0.24 \\
\hline S11 & 0.21 & -0.16 & 0.34 & 0.11 & 0.52 & & 0.67 & 0.20 & 0.00 & -0.32 & 0.17 \\
\hline $\mathrm{S} 15$ & 0.70 & 0.04 & 0.34 & -0.32 & 0.09 & 0.08 & & 0.18 & 0.07 & -0.33 & 0.14 \\
\hline $\mathrm{NH}$ & 0.11 & 0.61 & -0.06 & 0.00 & 0.40 & 0.28 & 0.23 & & -0.06 & -0.19 & 0.23 \\
\hline TL & -0.46 & -0.17 & -0.41 & 0.15 & -0.29 & 0.24 & -0.32 & -0.22 & & 0.61 & -0.03 \\
\hline EP & -0.70 & 0.02 & -0.64 & 0.31 & -0.62 & -0.20 & -0.53 & -0.34 & 0.66 & & -0.11 \\
\hline V & 0.30 & -0.46 & -0.19 & -0.57 & -0.49 & 0.26 & 0.07 & 0.05 & 0.21 & 0.13 & \\
\hline
\end{tabular}

\begin{tabular}{|c|c|c|c|c|c|c|c|c|c|c|c|}
\hline & DO & $\mathrm{NE}$ & RV & VG & S7 & S11 & S15 & $\mathrm{NH}$ & $\mathrm{TL}$ & EP & $\mathrm{V}$ \\
\hline$\overline{\mathrm{DO}}$ & & -0.50 & 0.21 & -0.04 & 0.13 & 0.47 & 0.28 & -0.63 & 0.38 & -0.02 & -0.33 \\
\hline $\mathrm{NE}$ & 0.62 & & -0.33 & 0.37 & 0.38 & -0.01 & 0.03 & 0.59 & -0.52 & -0.69 & -0.29 \\
\hline RV & 0.14 & -0.24 & & 0.17 & 0.29 & 0.11 & 0.43 & -0.44 & 0.52 & -0.08 & -0.01 \\
\hline VG & 0.42 & 0.42 & -0.07 & & 0.11 & -0.13 & 0.37 & 0.14 & -0.08 & -0.34 & -0.36 \\
\hline S7 & -0.22 & -0.38 & 0.27 & -0.38 & & 0.82 & 0.78 & 0.19 & 0.22 & -0.88 & 0.10 \\
\hline S11 & -0.50 & -0.32 & 0.24 & -0.14 & 0.24 & & 0.76 & 0.12 & 0.50 & -0.56 & 0.27 \\
\hline S15 & 0.36 & 0.07 & 0.28 & 0.09 & 0.23 & 0.21 & & 0.22 & 0.62 & -0.60 & 0.33 \\
\hline $\mathrm{NH}$ & -0.11 & 0.53 & -0.50 & 0.33 & -0.34 & 0.05 & -0.32 & & 0.05 & -0.25 & 0.52 \\
\hline TL & -0.08 & -0.28 & 0.32 & -0.38 & 0.02 & -0.08 & -0.13 & -0.24 & & 0.14 & 0.54 \\
\hline $\mathrm{EP}$ & -0.31 & -0.40 & 0.25 & -0.36 & 0.05 & 0.09 & -0.27 & -0.09 & 0.77 & & 0.20 \\
\hline V & -0.63 & -0.37 & -0.38 & -0.02 & 0.04 & 0.32 & -0.40 & 0.48 & -0.10 & 0.19 & \\
\hline
\end{tabular}

these limitations into account, we compared the rate and timing of developmental events of crested newt species at two temperatures. To analyse the differences in the embryonic developmental stages between species at each particular checkpoint (S7, S11, S15), we performed Friedman and Kruskal-Wallis tests. We then used a Mann-Whitney analysis to test for statistical significance in pair-wise comparisons. 


\section{Results}

\section{Survival rate}

Comparison of early life-history traits measured in this study revealed that all four species showed a similar pattern of survival rate with two critical periods (Table 1).

There was a large difference between the number of deposited eggs and the number of individuals that reached the late neurula stage (at the first checkpoint on day 7 of development). However, the highest peak of embryo mortality was recorded between the second and the third checkpoint (between 11 and 15 days of development). The examination of embryos at the third checkpoint revealed that in all four species, mortality occurred at the late tail bud stage. The high mortality at this stage is a result of the balanced lethal system that exists in crested newts, due to the homomorphism of heteromorphic chromosomes (Sims et al., 1984). The observed mortality rate at this stage was around $50 \%$ in all four species, which corresponds to the previously reported data for crested newts (D'Amen et al., 2006 and references therein). There were no differences in survival rate between $T$. dobrogicus, $T$. cristatus and $T$. arntzeni, while T.macedonicus had a significantly higher survival rate than the other three species (Table 1).

\section{Developmental and early life-history correlation pat- terns}

We investigated the pattern of correlation between all recorded life-history traits, including recorded devel-

Table 3. The analysis of correlation matrix patterns of eleven lifehistory and developmental traits. The observed coefficient of correlation between matrices $\left(R_{\mathrm{obs}}\right)$, and the robustness of correlation matrices and repeatability (the maximum possible correlation between matrix compared $\left(R_{\max }\right)$ and the values of adjusted matrix correlations $\left.\left(R_{\text {adj }}\right)\right)$ are presented. Probabilities were derived using Mantel's test with 10,000 iterations. Asterisks denote probabilities of $\mathrm{P}<0.05$, indicating that two matrices were more similar to each other than expected by chance.

\begin{tabular}{llll}
\hline Species compared & $R_{\mathrm{obs}}$ & $R_{\max }$ & $R_{\mathrm{adi}}$ \\
T. macedonicus - T. arntzeni & $0.465^{*}$ & 0.889 & 0.522 \\
T. macedonicus - T. dobrogicus & $0.304^{*}$ & 0.892 & 0.341 \\
T. macedonicus - T. cristatus & $0.520^{*}$ & 0.804 & 0.646 \\
T. arntzeni - T. dobrogicus & 0.189 & 0.851 & 0.222 \\
T. arntzeni - T. cristatus & $0.398^{*}$ & 0.767 & 0.519 \\
T. dobrogicus - T. cristatus & $0.327^{*}$ & 0.770 & 0.424 \\
& & & \\
\hline
\end{tabular}

opmental stages of embryos at three checkpoints during embryonic development. We calculated a correlation matrix for all analysed traits $(11 \times 11)$ separately for each species (Table 2).

Even though the phenotypic correlation matrices for some species were calculated for a relatively small number of cohorts $(N=19$ in $T$. cristatus $)$, the estimated matrices were highly reproducible and reliable (Table 3).

We found no correlation between the time of egg deposition and the number of deposited eggs per cohort, with the exception of T. dobrogicus, which exhibited a significant positive correlation between oviposition time and the number of eggs laid per cohort (Table 2). There was no correlation between the number of deposited eggs and vitellus size in any of the four species. A significant negative correlation was found between the vitellus size (RV) and the duration of embryonic period in T. macedonicus, while there was no significant relation between these two traits for other species. However, there was a strong positive correlation between the duration of embryonic period and the size of hatched larvae, except in T. cristatus (Table 2).

We applied Mantel's test to explore interspecific similarities in the correlation of life-history traits. Based on this analysis, the correlations of life-history traits in T. cristatus were concordant with the pattern observed in $T$. dobrogicus $(R=0.597, P<0.05)$, but were not similar to the other two species. The life-history trait correlation of $T$. dobrogicus also showed significant concordance with $T$. macedonicus $(R=0.688$, $P<0.01$ ), while the matrix correlation between $T$. dobrogicus and $T$. arntzeni was insignificant $(R=0.266$, $P>0.05)$. Triturus arntzeni had a similar correlation pattern to T. macedonicus $(R=0.450, P<0.05)$, but there were no similarities in the matrix correlation pattern compared to the other two species.

\section{Interspecific variability in embryonic development}

We performed a Kruskal-Wallis analysis to investigate interspecific variation in developmental rate (Figure 1). Based on our results, significant differences were found in all comparisons (at day 7, $H=131.05, P<$ 0.0001 ; at day $11, H=97.34, P<0.0001$ and at day $15, H=81.52, P<0.0001)$.

We conducted a pair-wise comparison of recorded embryonic stages at each checkpoint using a MannWhitney test. The results revealed interspecific variability at early stages in all comparisons, but only $T$. dobrogicus was significantly different from the other spe- 


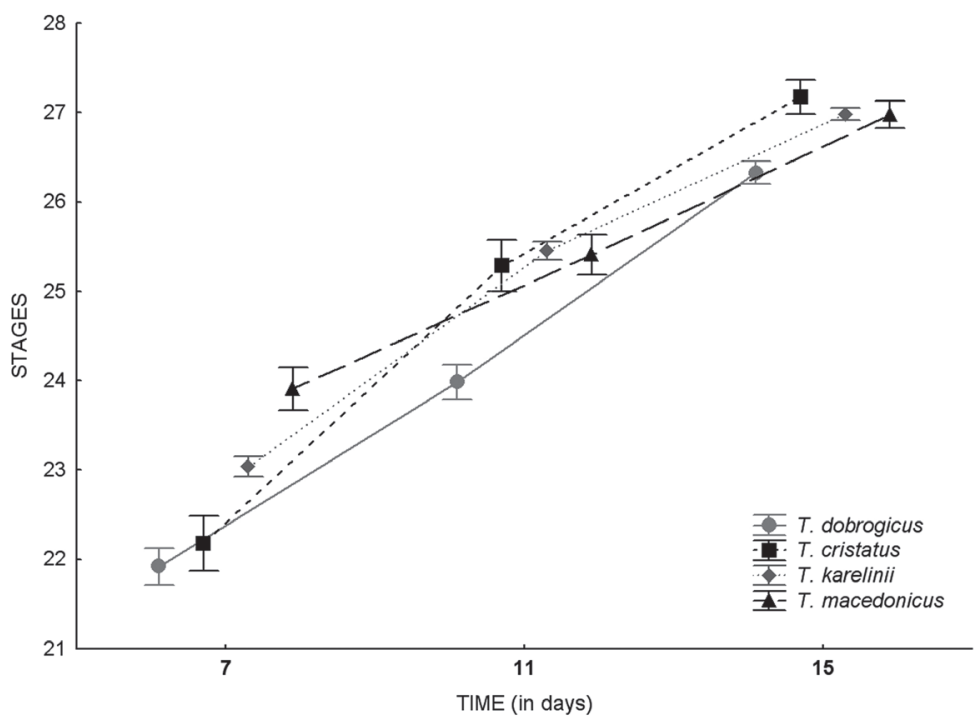

Fig. 1. Developmental stages at three different checkpoints ( $\mathrm{I}=7$ days, $\mathrm{II}=11$ days and $\mathrm{III}=15$ days) during embryonic development in four crested newt species. cies in later embryonic development. At day 7, all pairwise comparisons showed highly significant differences, except in the T. dobrogicus/T. cristatus comparison where differences were only marginally significant (Table 4). By day 11 of embryonic development, significant differences were observed only between $T$. dobrogicus and other species. The same pattern was observed at day 15 , and again only $T$. dobrogicus differed significantly in comparison to other species (Table 4).

\section{Discussion}

Although the embryonic development of all crested newts is similar in terms of the sequences of developmental stages and survival rate, species differ in the developmental rate and in the correlation pattern between analysed life-history and developmental traits. Triturus dobrogicus appears to be the outlier species, particularly in comparison to T. arntzeni and T. macedonicus, possessing the longest developmental period and a different timing of morphologically defined developmental events. Previously, we found that this species is also divergent with regard to postembryonic development, showing the smallest larval size at hatching and the longest larval period, which gives rise to the largest metamorphosed juveniles compared to the other species (Furtula et al., 2008, 2009). This suggests that the peculiarities of $T$. dobrogicus extend throughout ontogeny.

Differences in the sequence of developmental events, the timing and the rates of development are often invoked as causes that underlie observed phenotypic evolutionary changes (e.g. Ridley, 2003). In its most straightforward interpretation, our data suggest that heterochronic changes in early ontogeny can lead to lateral transposition of $T$. dobrogicus ontogenetic trajectories, as previously suggested for cranial shape (Ivanović et al., 2007) and allometric limb skeleton trajectories (Ivanović et al., 2008b). Additionally, two possible explanations can explain the differential embryonic pathway of $T$. dobrogicus. Since interspecific

Table 4. A pair-wise comparison of recorded embryonic stages at three checkpoints (S7, S11 and S15). The differences in developmental stages between species were tested using a Mann-Whitney test.

\begin{tabular}{|c|c|c|c|c|c|c|}
\hline \multirow[t]{2}{*}{ Species compared } & \multicolumn{2}{|c|}{ S7 } & \multicolumn{2}{|c|}{ S11 } & \multicolumn{2}{|c|}{ S15 } \\
\hline & $\underline{U}$ & $P$ & $U$ & $P$ & $U$ & $P$ \\
\hline T. macedonicus - T. arntzeni & 686.5 & 0.0001 & 1744 & 0.44 & 1212.0 & 0.86 \\
\hline T. macedonicus - T. dobrogicus & 365.5 & 0.0001 & 421.5 & 0.0001 & 969.0 & 0.0001 \\
\hline T. macedonicus - T. cristatus & 345.5 & 0.0001 & 587.0 & 0.18 & 587.0 & 0.18 \\
\hline T. arntzeni - T. dobrogicus & 2.5 & 0.0001 & 160.0 & 0.0001 & 205.5 & 0.0001 \\
\hline T. arntzeni - T. cristatus & 10.0 & 0.0001 & 281.0 & 0.76 & 123.5 & 0.24 \\
\hline T. dobrogicus - T. cristatus & 261.5 & 0.0465 & 110.5 & 0.0001 & 157.0 & 0.0001 \\
\hline
\end{tabular}


differences are present in the morphological traits of crested newts adults, it is possible that selection for adult traits have driven changes in developmental mechanisms at mid- and late embryonic stages, even though these stages are thought to be conserved in various vertebrate groups (Richardson, 1999; see also Richardson et al., 1997). Alternatively, evolutionary changes in patterning mechanisms during embryogenesis may be driven largely by ecological determinants, rather than by the need to produce particular adult morphologies (Wray, 2000; Chipman et al., 2000). This line of reasoning relates to the different ecological demands of crested newt species during embryogenic and post-metamorphic stages. This hypothesis can be regarded as a likely starting point to explain the autapomorphies of T. dobrogicus, obtained by rapid evolution at the developmental, morphological and life-history levels. These changes have occurred much faster in $T$. dobrogicus than in other species, regardless of the historical biogeography scenarios proposed for the evolution of crested newts (see Crnobrnja-Isailović et al., 1997; Arntzen et al., 2007). It can be speculated that during the evolution of crested newts, the major shift in terms of ecological preferences occurred when $T$. dobrogicus invaded the floodplains along the present-day Danube river and its tributaries which are covered with extensive swamps and marshes. This event, given the appropriate ecological opportunity, might have facilitated T. dobrogicus' acquisition of phenotypic innovations. Local selection involving major developmental shifts can produce rapid changes in ecological preferences, morphology and life-history, especially for groups with complex life cycles like newts, and therefore may hasten divergence. Here we prove that $T$. dobrogicus ontogeny is subject to considerable evolutionary change as well. Therefore, the evolution of the crested newt could be another example of an ecological switch paralleled by dramatic changes in phenotype (see Sol et al., 2005; and Herrel et al., 2008). In this case, these changes follow, as summarised above, the same general interspecific patterns for large amounts of independent data gathered for various morphological traits, including for complex structures (e.g. skull), as well as life-history, ecological and developmental characteristics. Such patterns are most likely due to the same cause, more likely the high level of phenotypic integration in crested newts rather than homoplasies.

Mapping developmental traits onto the crested newts' phylogeny strongly suggests that developmental traits of $T$. dobrogicus are derived when compared to character traits from species sharing a common an- cestor. In addition, the similarity of developmental traits of species from different clades (T. macedonicus, $T$. cristatus and $T$. arntzeni) might be due to the retention of ancestral characteristics rather than being independently acquired character states.

\section{Acknowledgements}

We gratefully acknowledge the thorough reviews provided by three anonymous reviewers which greatly improved the clarity of this article. This work was supported by the Serbian Ministry of Science under the project 'Patterns of Amphibian and Reptile Diversity on the Balkan Peninsula' (grant 143052). The experiments were approved by the Ethical Committee of the Institute for Biological Research 'Siniša Stanković' (nos. 6/06 and 3/08). All animals were collected under permits provided by the Ministry of Environmental Protection, Republic of Serbia (nos. 35301-309/2006-03; 353-01-111/2008-03), and the Institute for Nature Protection, Podgorica, Montenegro (no. 01-391/4).

\section{References}

Arntzen JW. 2003. Triturus cristatus Superspezies - KammolchArtenkreis. (Triturus cristatus (Laurenti, 1768) - Noërdlicher Kammolch, Triturus carnifex (Laurenti, 1768) - Italienischer Kammolch. Triturus dobrogicus (Kiritzescu, 1903) - DonauKammolch, Triturus karelinii (Strauch, 1870) - Suëdlicher Kammolch). Pp. 421-514 in: K. Grossenbacher, B. Thiesmeier, eds. Handbuch der Reptilien und Amphibien Europas, Band 4/IIA: Schwanzlurche (Urodela) IIA. Aula-Verlag, Wiebelsheim.

Arntzen JW, Wallis GP. 1999. Geographic variation and taxonomy of crested newts (Triturus cristatus superspecies): morphological and mitochondrial DNA data. Contributions to Zoology 68: 181-203.

Arntzen JW, Espregueira Themudo G, Wielstra B. 2007. The phylogeny of crested newts (Triturus cristatus superspecies): nuclear and mitochondrial genetic characters suggest a hard polytomy, in line with the paleogeography of the centre of origin. Contributions to Zoology 76: 261-278.

Bonacci A, Rizzuti MT, Tripepi S. 2005. Triturus alpestris inexpectatus: normal developmental stages morphology and temperature influence. Pp. 120-122 in: N Ananjeva and O Tsinenko, eds. Herpetologia Petropolitana.Societas Europaea Herpetologica St. Petersburg, 120-122.

Cheverud JM, Wagner GP, Dow MM. 1989. Methods for the comparative analysis of variation patterns. Systematic Zoology 38: 201-213

Chipman AD, Haas A, Tchernov E, Khaner O. 2000. Variation in anuran embryogenesis: differences in sequence and timing of early developmental events. Journal of Experimental Zoology (Mol Dev Evol) 288: 352-365.

Crnobrnja-Isailović J, Džukić G, Krstić N, Kalezić ML. 1997. Evolutionary and paleogeographical effects on the distribution of the Triturus cristatus superspecies in the central Balkans. Amphibia-Reptilia 18: 321-332. 
D’Amen M, Vignoli L, Bologna MA. 2006. The normal development and the chromosome No. 1 syndrome in Tritirus carnifex carnifex (Caudata, Salamandridae). Italian Journal of Zoology 73: 325-333.

D’Amen M, Vignoli L, Bologna MA. 2007. The effects of temperature and $\mathrm{pH}$ on the embryonic development of two species of Triturus (Caudata: Salamandridae). Amphibia-Reptilia 28: 295-300.

Efron B,Tibshirani RJ. 1993. An introduction to the bootstrap. Chapman and Hall.

Epperlein HH, Junginger M. 1982. The normal development of the newt, Triturus alpestris (Daudin). Amphibia-Reptilia 2: 295-308

Espregueira Themudo G, Wielstra B, Arntzen JW. 2009. Multiple nuclear and mitochondrial genes resolve the branching order of a rapid radiation of crested newts (Triturus, Salamandridae). Molecular Phylogenetics and Evolution 52: 321-328.

Furtula M, Ivanović A, Džukić G, Kalezić ML. 2008. Egg size variation in crested newts from the western Balkans (Caudata: Salamandridae: Triturus cristatus superspecies). Zoological Studies 47: 585-590.

Furtula M, Todorović B, Simić V, Ivanović A. 2009. Interspecific differences in early life-history traits in crested newts (Triturus cristatus superspecies, Caudata, Salamandridae) from the Balkan Peninsula. Journal of Natural History 43: 469-477.

Geller S. 1983. Statistique. Paris: Masson.

Griffiths RA, de Wijer P. 1994. Differential effects of $\mathrm{pH}$ and temperature on embryonic development in the British newts (Triturus). Journal of Zoology 234: 613-622.

Hall BK. 1999. Evolutionary Developmental Biology. 2nd ed. Dordrecht: Kluwer Academic Publishers.

Hall BK. 2003. Evolution as the control of development by ecology. Introduction in: Müller GB, Wagner GP, Callebaut W, eds. Environment, Development and Evolution: Toward a Synthesis. (The Vienna Series in Theoretical Biology), A Bradford Book, Massachusetts.

Hansen TF, Martins EP. 1996. Translating between microevolutionary process and macroevolutionary patterns: The correlation structure of interspecific data. Evolution 50: 1404-1417.

Herrel A, Huyghe K, Vanhooydonck' B, Backeljau T, Breugelmans K, Grbac I, Van Damme R, Irschick DJ. 2008. Rapid large-scale evolutionary divergence in morphology and performance associated with exploitation of a different dietary resource. Proceedings of the National Academy of Science 105: 4792-4795.

Hood G. 2004. Poptools, ver. 2.62. CSIRO, Canberra. http:// www.cse.csiro.au/poptools.

Ivanović A, Vukov TD, Tomašević N, Džukić G, Kalezić ML. 2007. Ontogeny of skull size and shape changes within a framework of biphasic lifestyle: A case study in six Triturus species (Amphibia, Salamandridae). Zoomorphology 126: 173-183.

Ivanović A, Sotiropoulos K, Vukov TD, Eleftherakos K, Džukić G, Polymeni R, Kalezić ML. 2008a. Cranial shape variation and molecular phylogenetic structure of crested newts (Triturus cristatus superspecies: Caudata, Salamandridae) in the Balkans. Biological Journal of the Linnean Society 95: $348-360$

Ivanović A, Tomašević N, Džukić G, Kalezić ML. 2008b. Evolutionary diversification of the limb skeleton in crested newts
(Triturus cristatus superspecies, Caudata, Salamandridae). Annales Zoologici Fennici 45: 527-535.

Ivanović A, Sotiropoulos K, Furtula M, Džukić G, Kalezić ML. 2008c. Sexual size and shape evolution in European newts (Amphibia: Caudata: Salamandridae) on the Balkan Peninsula. Journal of Zoological Systematics and Evolutionary Research 46: 381-387.

Klingenberg CP. 2004. Integration, modules and development: molecules to morphology to evolution. Pp. 213-230 in: M. Pigliucci and K. Preston, eds. Phenotypic Integration: Studying the Ecology and Evolution of Complex Phenotypes. New York, Oxford University Press, 213-230 .

Knight FCE. 1938. Die Entwicklung von Triton alpestris bei verschiedenen Temperaturen mit Normentafel. Roux' Archiv für Entwicklungsmechanik 137: 461-473.

Litvinchuk SN, Rosanov JM, Borkin LJ. 2007. Correlations of geographic distribution and temperature of embryonic development with the nuclear DNA content in the Salamandridae (Urodela, Amphibia). Genome 50: 333-342.

Marroig G, Cheverud JM. 2001. A comparison of phenotypic variation and covariation patterns and the role of phylogeny, ecology and ontogeny during cranial evolution of new world monkeys. Evolution 55: 2576-2600.

Miaud C. 1994. Role of wrapping behavior on egg survival in three species of Triturus (Amphibia: Urodela). Copeia 1994: 535-537.

Nieuwkoop PD. 1996. What are the key advantages and disadvantages of urodele species compared to anurans as a model system for experimental analysis of early development? International Journal of Developmental Biology 40: 617-619.

Revell LJ, Harmon LJ, Collar DC. 2008. Phylogenetic signal, evolutionary process, and rate. Systematic Biology 57: 591601.

Richardson MK. 1999. Vertebrate evolution: the developmental origins of adult variation. BioEssays 21: 604-613.

Richardson MK, Hanken J, Gooneratne ML, Pieau C, Raynaud A, Selwood L, Wright GM. 1997. There is no highly conserved embryonic stage in the vertebrates: implications for current theories of evolution and development. Anatomy and Embryology 196: 91-106.

Ridley M. 2003. Evolution. Wiley-Blackwell.

Sims SH, Macgregor HC, Pellatt PS, Horner HA. 1984. Chromosome I in crested and marbled newts (Triturus). Chromosoma 89: 169-185.

Sol D, Duncan RD, Blackburn TM, Cassey P, Lefebvre L. 2005. Big brain, enchaced cognition, and response of birds to novel environments. Proceedings of the National Academy of Science 102: 5460-5465.

Vukov TD, Ivanović A, Tomašević N, Džukić G, Kalezić ML. 2007. Braincase-body size relations in European newts (Triturus spp.: Salamandridae: Caudata): Does the size matter? Annales Zoologici Fennici 44: 232-239.

Wray GA. 2000. The evolution of embryonic patterning mechanisms in animals. Seminars in Cell and Developmental Biology 11: 385-393.

Received: 17 March 2009

Accepted: 30 June 2009

Published online: 11 August 2009

Editor: J.W. Arntzen 